\title{
RECOMENDAÇÃO DE ADUBAÇÃO E CALAGEM PARA COQUEIRO (Cocos nucifera L.) NO ESTADO DE SÃO PAULO - 1 $^{\mathrm{a}}$. APROXIMAÇÃO ${ }^{1}$
}

\author{
LUIZ ANTONIO JUNQUEIRA TEIXEIRA², ONDINO CLEANTE BATAGLIA³, SALATIÉR BUZETTI ${ }^{4}$, \\ ENES FURLANI JUNIOR ${ }^{4}$
}

RESUMO - O objetivo deste trabalho foi apresentar a $1^{\text {a }}$. aproximação da recomendação de adubação e calagem para coqueiro no Estado de São Paulo, visando à produção de água. O cultivo de coqueiro nesta região é recente, carecendo de recomendações técnicas. Esta recomendação foi elaborada a partir de resultados experimentais obtidos em campo e de informações disponíveis na literatura. A recomendação de adubação segue os padrões do Boletim Técnico 100 do Instituto Agronômico (SP). Nas tabelas apresentadas, as doses de fertilizantes são obtidas com base nos teores de $\mathrm{P}$ e K disponíveis no solo, na idade das plantas durante a formação do coqueiral (até 5 anos) e, posteriormente (fase de produção), na produtividade esperada.

Termos para indexação: análise de solo, coco, fósforo, nitrogênio, potássio

\section{FERTILIZER AND LIME RECOMMENDATION FOR COCONUT (Cocos nucifera L.) IN THE STATE OF SÃO PAULO, BRAZIL - $1^{\text {ST }}$ VERSION}

ABSTRACT - The objective of this publication was to introduce the $1^{\text {st }}$ version of fertilizer and lime recommendation for coconut cropped in the State of São Paulo, Brazil. This recommendation was based on field results from an experiment and on literature review. The recommendation followed the guidelines of the Technical Bulletin 100, issued by Instituto Agronômico (SP, Brazil). Fertilizer rates are assessed based on soil available nutrients ( $\mathrm{P}$ and $\mathrm{K}$ ), plant age for young palms (up to 5 year) and expected yield for adult palms ( $>5$ year).

Index terms: fertilization, nitrogen, phosphorus, potassium, soil analysis

O cultivo de coqueiro no Estado de São Paulo teve grande expansão nos últimos anos visando a atender o mercado de água de coco. Em 1993, havia cerca de 100 ha cultivados com coco no Estado, que aumentou para 2.600 ha em 2003 (IBGE, 2005). O cultivo comercial de coqueiro é relativamente novo no Sudeste e, diante da falta de informações específicas para esta região do País, muitos plantios foram realizados com base em recomendações técnicas da região Nordeste.

O objetivo desta Comunicação Científica é colocar em discussão proposta de recomendação de adubação e calagem para coqueiro visando à produção de água. A partir desta $1^{\mathrm{a}}$. aproximação, pretende-se chegar a uma recomendação para a cultura baseada em experimentação e adequada às condições de cultivo do Estado de São Paulo.

Essa recomendação foi elaborada a partir de resultados obtidos num experimento de campo relatados por Teixeira et al. (2005a, 2005b) e em informações disponíveis na literatura.

O modelo da recomendação seguiu os padrões do Boletim Técnico 100 do Instituto Agronômico (Raij et al., 1997). Nessa recomendação, empregou-se o conceito de produtividade esperada que, basicamente, reflete a relação de que culturas mais produtivas requerem maior quantidade de nutrientes. Entretanto, essa produtividade dependerá de outros fatores além do manejo da fertilidade, como potencial da planta cultivada, clima, práticas culturais, entre outros. Outra variável determinante da dose de fertilizante a ser recomendada é o resultado da análise do solo. Em São Paulo, a disponibilidade de nutrientes no solo (P e K) é estimada por meio de extração com resina trocadora de íons.
Por tratar-se da $1^{\text {a }}$. aproximação, os autores esperam contar com contribuições da comunidade de técnicos e usuários envolvidos com o cultivo de coqueiro visando à produção de água, a fim de tornar essa recomendação um instrumento útil para a cultura no Estado de São Paulo. Posteriormente, essa recomendação deverá ser incluída na próxima edição do Boletim Técnico 100 do IAC (Recomendações de adubação e calagem para o Estado de São Paulo). Antes, provavelmente, estas tabelas serão incorporadas à versão eletrônica do BT 100 .

\section{RECOMENDAÇÃO DEADUBAÇÃOE CALAGEM PARA COQUEIRO}

Espaçamento: 7,5 x 7,5 x 7,5 m, em triângulo (205 plantas/ha)

Calagem: aplicar calcário para elevar a saturação por bases a $60 \%$ e o magnésio a um teor mínimo de $5 \mathrm{mmol} / \mathrm{cm}^{3}$.

Adubação de plantio: aplicar 20 litros/cova de esterco de curral ou composto, ou 4 litros de esterco de galinha bem curtidos em mistura com $100 \mathrm{~g}$ de $\mathrm{P}_{2} \mathrm{O}_{5}$ e $5 \mathrm{~g}$ de $\mathrm{Zn}$. Os adubos devem ser bem misturados com a terra 20 a 30 dias antes do plantio.

Adubação de formação: aplicar, de acordo com a análise do solo inicial e a idade das plantas, as quantidades indicadas na Tabela 1.

Fracionar as doses em três aplicações durante a estação chuvosa, aproximadamente em outubro, dezembro e março para as condições de São Paulo. Aplicar os adubos na área de coroamento das plantas, numa faixa circular de aproximadamente $1 \mathrm{~m}$ de largura e distante $30 \mathrm{~cm}$ do caule.

TABELA 1 - Adubação de formação.

\begin{tabular}{|c|c|c|c|c|c|c|c|}
\hline \multirow{2}{*}{ Idade } & \multirow{2}{*}{ Nitrogênio } & \multicolumn{3}{|c|}{$P$ resina, $\mathrm{mg} / \mathrm{dm}^{3}$} & \multicolumn{3}{|c|}{$\mathrm{K}^{+}$trocável, $\mathrm{mmol}_{\mathrm{c}} / \mathrm{dm}^{3}$} \\
\hline & & $0-12$ & $13-30$ & $>30$ & $0-1,5$ & $1,6-3,0$ & $>3,0$ \\
\hline 0 a 1 & 120 & 0 & 0 & 0 & 240 & 180 & 120 \\
\hline 2 a 3 & 360 & 270 & 180 & 90 & 720 & 540 & 360 \\
\hline 3 a 4 & 480 & 360 & 240 & 120 & 960 & 720 & 480 \\
\hline 4 a 5 & 600 & 450 & 300 & 150 & 1200 & 900 & 600 \\
\hline
\end{tabular}

\footnotetext{
${ }^{1}$ (Trabalho 094/2005). Recebido: 03/06/2005. Aceito para publicação: 17/11/2005. Apoio da FAPESP (Proc. 00/09417-1)

${ }^{2}$ Pesquisador do Instituto Agronômico - IAC, Cx. Postal 28, 13001-970, Campinas-SP, teixeira@iac.sp.gov.br.

${ }^{3}$ Pesquisador do Instituto Agronômico - IAC, bolsista do CNPq, ondino@iac.sp.gov.br.

${ }^{4}$ Professores da FEIS/UNESP. Ilha Solteira-SP, sbuzetti@agr.feis.unesp.br; enes@agr.feis.unesp.br.
} 
TABELA 2 - Adubação de produção.

\begin{tabular}{|c|c|c|c|c|c|c|c|c|}
\hline \multirow{2}{*}{\multicolumn{2}{|c|}{ Produtividade esperada }} & \multirow{2}{*}{ Nitrogênio } & \multicolumn{3}{|c|}{ P resina, $\mathrm{mg} / \mathrm{dm}^{3}$} & \multicolumn{3}{|c|}{$\mathrm{K}^{+}$trocável, $\mathrm{mmol}_{\mathrm{c}} / \mathrm{dm}^{3}$} \\
\hline & & & $0-12$ & $13-30$ & $>30$ & $0-1,5$ & $1,6-3,0$ & $>3,0$ \\
\hline t/ha & $\begin{array}{l}\text { frutos por } \\
\text { planta }^{(1)}\end{array}$ & $\mathrm{N}, \mathrm{kg} / \mathrm{ha}$ & \multicolumn{3}{|c|}{------------ $\mathrm{P}_{2} \mathrm{O}_{5}, \mathrm{~kg} / \mathrm{ha}$---------- } & \multicolumn{3}{|c|}{------------ $\mathrm{K}_{2} \mathrm{O}$, kg/ha --------- } \\
\hline$<20$ & $<60$ & 80 & 60 & 30 & 0 & 180 & 120 & 60 \\
\hline $20-30$ & $60-90$ & 120 & 90 & 60 & 30 & 240 & 180 & 120 \\
\hline$>30$ & $>90$ & 160 & 120 & 90 & 60 & 300 & 240 & 180 \\
\hline
\end{tabular}

(1) Estimativa considerando 205 plantas/ha e frutos com aproximadamente $1,6 \mathrm{~kg}$.

Adubação de produção: aplicar, de acordo com a análise do solo e a produção anual esperada, as quantidades indicadas na Tabela 2.

Da mesma forma que na formação das plantas, fracionar a adubação em três aplicações na estação chuvosa. Continuar aplicando os adubos na área de coroamento das plantas, mas aumentar a largura da faixa adubada para $1,5 \mathrm{~m}$.

A partir do $2^{\circ}$ ano, aplicar $30 \mathrm{~kg} / \mathrm{ha} / \mathrm{ano}$ de enxofre. Adubar com zinco (5 kg/ha de $\mathrm{Zn})$ sempre que a análise de solo indicar valores abaixo de $0,6 \mathrm{mg} / \mathrm{dm}^{3}$ (DTPA). Aplicar boro ( $2 \mathrm{~kg} / \mathrm{ha}$ de B) quando a análise indicar teores abaixo de $0,2 \mathrm{mg} / \mathrm{dm}^{3}$ (água quente).

\section{REFERÊNCIAS}

IBGE. Instituto Brasileiro de Geografia e Estatística. Disponível em: $<$ http://www.ibge.gov.br $>$. Acesso em: 28 abr. 2005.

JEGANATHAN, M. Studies on potassium-magnesium interaction in coconut (Cocos nucifera). In: Van BEUSICHEM, M.L. (Ed.). Plant nutrition: physiology and applications. Wageningen: Kluwer Academic Publisher, 1990. p.611-77.(não consta no texto)

KHAN, H.H.; BIDDAPPA, C.C.; JOSHI, O.P. A review of Indian work on phosphorus nutrition of coconut. Journal of Plantation Crops, Kasarogod, v.13, n.1, p.11-21, 1985.

MAGAT, S.S. Coconut. In: World fertilizer use manual. International Fertilizer Association (IFA). 2005. Disponível em: $<\underline{\text { http: } / /}$ www.fertilizer.org/ifa/publicat/html/pubman/coconut.htm>. Acesso em: 11 abr. 2005. (não consta no texto)
OUVRIER, M. Exportation par la récolte du cocotier PB-121 em function de la fumure potassique et magnésienne. Oléagineux, Montpellier, v.39, p.263-71, 1984. (não consta no texto)

RAIJ, B. Van; CANTARELLA, H.; QUAGGIO, J.A.; FURLANI, A.M.C. (Ed.) Recomendações de adubação e calagem para o Estado de São Paulo. 2.ed. Campinas: IAC, 1997. 285p. (Boletim Técnico, 100)

ROGNON, F. Cocotier. In: MARTIN-PRÉVEL, P.; GAGNARD, J.; GAUTIER, P. (Ed.) L'analyse végétale dans le contrôle de l'alimentation des plantes tempérées et tropicales. Paris: Tec\&Doc, 1984. p.447-57. (não consta no texto)

SANTOS, Z.G. Adubação da cultura do coco. Aracaju: IPEAL, 1972. 8p. (Série Monografia, 6) (não consta no texto)

SOBRAL, L.F. Nutrição e adubação do coqueiro. In: FERREIRA, J.M.S.; WARWICK, D.R.N.; SIQUEIRA, L.A. A cultura do coqueiro no Brasil. 2.ed. Aracaju: EMBRAPA-CPATC,1997. p.129-157.

SOBRAL, L.F.; SANTOS, Z.G. Sistema de recomendações de fertilizantes para o coqueiro (Cocos nucifera L.) com base na análise foliar. Brasília: EMBRAPA-DDT, 1987.23p. (Documentos, 7) (não consta no texto)

TEIXEIRA, L.A.J.; BATAGLIA, O.; BUZETTI, S.; FURLANI JR., E. Adubação com NPK em coqueiro anão-verde (Cocos nucifera L.) atributos químicos do solo e nutrição da planta. Revista Brasileira de Fruticultura, Jaboticabal, v.27, n.1, p.115-119, 2005 a.

TEIXEIRA, L.A.J.; BATAGLIA, O.; BUZETTI, S.; FURLANI JR., E.; ISEPON, J. S. Adubação com NPK em coqueiro anão-verde (Cocos nucifera L.) - rendimento e qualidade de frutos. Revista Brasileira de Fruticultura, Jaboticabal, v.27, n.1, p.120-123, 2005b. 